\section{Uma contribuição ao debate de saúde global}

\section{A contribution to the global health debate}

DEATON, Angus. A grande saida: saúde, riqueza e as origens da desigualdade. Rio de Janeiro, Intrínseca, 2017. $336 \mathrm{pp}$.

\section{Nicole Aguilar Gayard}

https://orcid.org/0000-0001-9034-6846

Pesquisadora do Centro Brasileiro de Análise e Planejamento (Cebrap), São Paulo - SP, Brasil.

E-mail: nicolegayard@gmail.com.

DOI: $10.1590 / 349907 / 2019$

Angus Deaton, microeconomista e professor de Princeton, foi vencedor do Prêmio de Ciências Econômicas (erroneamente chamado "Nobel de Economia”) em 2015, devido à sua análise sobre consumo, pobreza e bem-estar. A Academia Real das Ciências da Suécia, que realiza a premiação, julgou a contribuição do autor à compreensão de escolhas individuais fundamental para novas concepções na elaboração de políticas de bem-estar e redução da pobreza.

Entre as contribuiçôes mais recentes do autor consideradas pela premiação, destaca-se o trabalho sobre medidas de padróes de vida e pobreza de países em desenvolvimento com uso de dados microeconômicos de consumo, obtidos por surveys domiciliares, em lugar de dados de renda, apontados como menos confiáveis para compreender o bem-estar em contextos sociais distintos. Além disso, a obra de Deaton sinalizou limites que existem na comparação e medição de pobreza entre diferentes países conduzidas por meio de cálculos de "linha de pobreza", que aponta um mesmo valor-base mínimo sem avaliar o grau de desigualdade interna e, portanto, insuficiente para aferir dados como qualidade do bem consumido ou diferentes padrôes culturais de consumo. $\mathrm{O}$ autor propôs diferentes medidas e variáveis para analisar o bem-estar de pessoas de baixa renda, levando em conta, por exemplo, a relação entre renda e consumo de calorias e a apreciação da existência de discrimi- nação entre gêneros intrafamiliares. Seu legado de pesquisa até aqui é considerado de grande relevância para medidas de pobreza em países em desenvolvimento e índices de comparação internacional, e apresenta relevante contribuição na transformaçáo do campo de desenvolvimento econômico em um campo empírico (The Royal Swedish Academy of Sciences, 2015).

A grande saida apresenta, de maneira didática, muitos dos argumentos relacionados com as inovações propostas por Deaton para a medição de bem-estar e desigualdade internacionais. O livro foi publicado em inglês em 2013 e teve sua versão traduzida publicada no Brasil em 2017. Congrega questôes e temas cruciais para debates sobre o desenvolvimento global contemporâneo ao prometer uma abordagem de bem-estar mais ampla que as tradicionais, que inclua consideraçóes, mediçóes e análises de saúde. Não obstante a publicação original ter sido parcialmente ofuscada nos debates econômicos e sociais pela obra "O capital", de Thomas Piketty, lançada pouco antes, $A$ grande saida recobra sua relevância no contexto da ascensão e reconhecimento da temática da saúde como elemento fundamental na política internacional contemporânea.

O livro traz um olhar aprofundado da evolução da saúde em escala global com muita clareza, apontando para temas e questóes centrais, e fornece diferentes perspectivas para compreender a área de forma holística. O livro é dividido em três grandes partes, sendo a parte 1 composta de três capítulos e dedicada à temática da saúde, a parte 2 composta de dois capítulos e dedicada aos padróes de vida e a parte 3 composta de um capítulo, em que se discute a ajuda internacional.

O prefácio e a introdução estabelecem o panorama de análise proposto. Trata-se de ampliar o debate sobre desenvolvimento e desigualdade complementando-o com uma atenção à saúde. Embora Deaton reconheça que a inclusão da saúde, por si só, não seja suficiente para completar o retrato do bem-estar, que também é afetado por outros aspectos (como liberdade, educação, dignidade), sua incorporação à análise confere um retrato muito mais completo para concepçóes e mediçóes de bem-estar que o tradicional produto interno bruto (PIB) e suas variantes. 
A construção do texto se dá em torno da metáfora de "grande saída", que seria a fuga da pobreza, por meio de melhorias dos padróes de vida. Essa saída implica, em parte, o progresso técnico, que confere melhores condições de vida à população e explica por que todos vivemos, em geral, melhor que nossos antepassados, e em parte, o empenho e a sorte individuais, relativos àqueles que conseguem construir uma rota de fuga enquanto outros permanecem na situação da pobreza extrema. É com foco nessa dúbia identidade do progresso tanto individual (pautada no mérito ou na sorte) e excludente, como comunitária e, portanto, compartilhada - que os argumentos do autor em torno da fuga da pobreza mundial e da promoção do desenvolvimento global se constroem. Este pode ser um motivo de desconforto ao longo da leitura: no decorrer do texto, as análises se constroem ora com base em entendimentos absolutos (em que as realidades de países em desenvolvimento são percebidas como uma só), ora reconhecendo a dificuldade de medir valores mais subjetivos em diferentes culturas e contextos (ao explorar a dificuldade de comparaçóes com base em índices colhidos em cada país, por exemplo). A sensação é de que prevalece, ao longo do livro, uma percepção universalizante do progresso que apontaria para uma "saída padrão", consistindo em admitir a desigualdade dentro de algum limite, de modo a não apresentar obstáculos à participação democrática. Não obstante, a desigualdade teria como resultado positivo a permanente busca pelo progresso individual, permitindo benefícios comuns, como a continuidade de pesquisas em saúde. Para Deaton, a inclusão da saúde na análise de desenvolvimento sugere um espaço para a distribuição dos benefícios do progresso mais frutífera que simplesmente a distribuição de renda. Não obstante, não se apresenta, nestes capítulos e ao longo do livro, uma alternativa para efetivar tal distribuição ou torna-la mais eficiente e equitativa.

O capítulo 1 se dedica a apresentar um panorama do mundo atual, com foco no crescimento e desigualdade. Esse panorama se centra nos temas saúde e riqueza, e reconhece o progresso e a ampliação da desigualdade internacional nas duas áreas. $\mathrm{O}$ autor também constrói associações entre estes temas, mostrando que quanto mais pobre um país, piores tendem a ser suas estatísticas de saúde. Aponta, no entanto, que a conexão entre expectativa de vida e pobreza está longe de ser exata, uma vez que países muito populosos, mesmo com grandes economias (Índia e China) podem ter expectativas de vida menores que países menores e mais pobres (Bangladesh e Nepal); enquanto países ricos, como os Estados Unidos, podem apresentar uma situação pior que a renda faria supor, com grande contingente de pessoas pobres e sem acesso facilitado a serviços de saúde. O capítulo também sugere uma associação entre saúde, riqueza e bem- estar, apontando para esforços de identificar melhorias de bem-estar no âmbito individual, usando critérios apontados pelos próprios indivíduos. Nessa discussão, insere questóes sobre diferentes percepçóes possíveis, bem-estar emocional e felicidade, que se associam a e desafiam mediçôes de bem-estar. Os dados apresentados ao longo do capítulo, não obstante, indicam uma tendência contínua à evolução na expectativa de vida a todos os países, que será posteriormente associada ao argumento do demógrafo Samuel Preston, que em 1975 sugeriu que a ampliação na expectativa de vida não seria explicada por renda, mas por aumento no conhecimento e progressos na saúde.

O capítulo 2 inaugura a parte 1 do livro, intitulada "Vida e morte", e promove uma revisão histórica da saúde, desde a Pré-História até 1945. O autor traça, a partir de dados históricos, um quadro de contínuo progresso nas expectativas de vida em todas as classes sociais e países, atribuído a grandes inovaçóes (como inoculação da varíola e saneamento) e a mudanças nos padrôes de vida (como diminuição do tabagismo). O capítulo fornece uma rica revisão de inovaçôes cruciais para a melhoria dos níveis de saúde, com uma discussão aprofundada em diferentes períodos da história inglesa, conferindo importante base para compreender a evolução dos cenários e temas da saúde internacional.

O capítulo 3 se dedica ao estado da arte da saúde no mundo em desenvolvimento (ao que o autor se refere no título como "trópicos"), no período pós-1945. A partir da consideração de que a chave do aumento da expectativa de vida reside no conhecimento, demonstra que o progresso em saúde foi mais rápido nos países em desenvolvimento do 
que foi ao longo da história, uma vez que o conhecimento e soluçóes produzidas nos contextos que se depararam pela primeira vez com determinadas doenças (neste caso, países desenvolvidos) se difundiu. A difusão internacional do conhecimento consiste, portanto, em um aspecto chave do progresso em saúde e bem-estar. Um dado relevante na comparação internacional é que "as diferenças nas expectativas de vida, que se ampliaram a partir de 1850 , quando os países ricos melhoraram seus índices, diminuíram depois de 1950 e voltaram a crescer com a eclosão da nova epidemia [de Aids]" (p. 99). A atenção também é colocada no fato de que um número assustadoramente alto de crianças morrem em decorrência de doenças para as quais já existe tratamento. $\mathrm{O}$ capítulo apresenta diferentes períodos em que o fosso entre ricos e pobres, em termos de saúde, se ampliou ou diminuiu.

Mais uma vez, o autor traz dados relevantes e levanta pontos fundamentais para o debate da saúde global contemporânea. Aponta para atores internacionais que foram fundamentais no manejo da saúde no mundo em desenvolvimento, bem como na diminuição da morte e de doenças em diversas partes do mundo, como o Fundo das $\mathrm{Na}$ ções Unidas para a Infância (Unicef), a Organização Mundial da Saúde (OMS) e a Aliança Global para Vacinas e Imunização (Gavi). O autor mostra que o crescimento econômico não elimina automaticamente a morte decorrente de doenças tratáveis em muitos países em desenvolvimento. Há diversas causas de mortes e formas de lidar com cada uma, e Deaton oferece um esforço de atenção à diversificação de soluçôes para a "saída", para diferentes situaçôes e enfermidades. Não obstante, o autor não discute um tema quente no debate sobre saúde global contemporâneo: o papel do governo na provisão de serviços públicos versus sistemas privados de saúde. A opção dos sistemas públicos de saúde é bastante contemporizada, e o texto focaliza as inúmeras variáveis que poderiam influir no seu funcionamento, sem, contudo, adentrar o debate público/privado.

O capítulo 4 encerra a primeira parte do livro e apresenta a saúde no mundo moderno, com enfoque nas pessoas de meia-idade e idosos. Apresenta os principais desafios de saúde no mundo desenvolvido, em relação a problemas de saúde como fumo, doenças cardiovasculares, câncer e alimentação. Traz propostas para pensar em diferentes estilos de financiamento à pesquisa em saúde, comparando o sistema americano e inglês. Aponta, de forma cuidadosa, para questóes relativas ao custo de tratamento e às escolhas sociais que devem ser feitas em relação à alocação de serviços em saúde - o quanto é suficiente ou justo, e para quais tratamentos? Do que se abre mão em nome do tratamento de problemas de saúde que não são questão de vida? Reconhecendo que em lugares em que a expectativa de vida já é alta o desafio de aumentá-la fica maior, o autor explora a dificuldade de medir progressos em saúde e defende o (controverso) argumento, de que é possível relacionar saúde, inteligência e nutrição com altura.

A parte 2, "Dinheiro", se inicia com o capítulo 5, que discute o bem-estar material nos Estados Unidos e serve de parâmetro para pensar a realidade dos países ricos. O capítulo discute várias limitaçóes do PIB como medida de renda - como o fato de não incluir impostos e, portanto, não permitir que se considerem gastos públicos como fator de melhoria de bem-estar. Aponta a dificuldade das métricas econômicas tradicionais em refletir as melhorias nos padrôes, bens e serviços que consumimos. Coloca, ainda, a discussão sobre gastos de saúde e a dificuldade em atribuir valor aos mesmos com base na lei de oferta e demanda. Para Deaton, novos e melhores produtos são de grande importância para explicar o crescimento econômico, e estas melhorias não são percebidas nas métricas tradicionais.

O capítulo também discute os limites e potencialidades da "linha da pobreza" para pensar o crescimento, a desigualdade e a situação de bem-estar das camadas mais pobres. Aponta para o crescimento das desigualdades intranacionais e promove um amplo debate em torno do princípio de Pareto (de que se todos estiverem melhores que num ponto inicial, não importa o nível de desigualdade), ao reconhecer que o potencial daqueles com maior concentração de poder aquisitivo de influenciar as políticas é determinante e deve ser levado em consideração nos debates. Aponta, ainda, para fatores de desigualdade no trabalho, o papel das políticas na redistribuição ou promoção de melhorias de bem-estar, considerando outras variáveis além da renda. 
O capítulo 6 discute a globalização, tomada como um fator positivo para a promoçáo da "fuga". Discute de maneira pormenorizada outro índice, o de paridade do poder de compra (PPC), avaliando-o como controverso, mas útil para medir realidades de acesso a bens básicos entre naçóes. $\mathrm{O}$ capítulo participa do debate sobre desigualdade e globalização, apontando que a globalização não aumentou a desigualdade entre naçóes, mas sim desigualdades intranacionais, que permanecem um fator preocupante a ser equacionado.

Há uma diversidade de experiências em relação aos países pobres, marcada pelo alto crescimento em alguns e estagnação em outros. Umas das respostas aventadas por Deaton para a dificuldade em sustentar a saída é que "países pobres carecem de instituiçóes - capacidade do Estado, sistema legal e tributário eficaz, garantia de direito à propriedade privada e confiabilidade - que são base indispensável para que haja crescimento" (p. 214). O mundo em desenvolvimento é discutido, ao longo do capítulo, tendo como referência China, Índia (os países mais populosos e, por isso, relevantes para a pobreza global) e a África. Nesse sentido, cabe notar que o autor fornece um diagnóstico totalizante do mundo em desenvolvimento, a despeito de apontar para a diversidade de experiências de saúde.

A parte final, "Ajuda”, consiste em um único capítulo que discute a ajuda internacional, que é apresentada como alternativa fundamental, aventada pelos países ricos, para solucionar a questão da miséria global ou pensar o desenvolvimento internacional. Deaton apresenta fortes críticas a esse modelo, seguindo uma linha de argumentação centrada no fato de que a ajuda internacional não elimina a pobreza (nem se propóe a fazê-lo), mas é muito diversificada em seus objetivos e, em muitos casos, sujeita a corrupção. Além disso, ao não ser efetiva na transformação em larga escala dos países recebedores, e porque seus benefícios são de difícil mensuração, os riscos e problemas são excessivos e prejudicam, inclusive, mudanças internas na realidade política e de governo de muitos países, que poderiam ser realizadas se não houvesse ajuda.

Muitos dos argumentos trazidos pelo autor são comuns nos debates sobre ajuda internacional. Há, no final do capítulo, um tópico dedicado à ajuda em saúde, no qual, sem fornecer dados, o autor defende que projetos verticais (estabelecidos pelo doador de cima para baixo e direcionados a doenças específicas) tendem a ser mais efetivos que horizontais (ampliação da atenção à saúde, consultas periódicas e tratamento de diversos problemas de saúde), devido à dificuldade de garantir um funcionamento adequado das instituiçóes de saúde nos países em que a ajuda é implementada.

Os argumentos do último capítulo carecem de melhor fundamentação em dados, o que difere largamente do restante do livro, e apontam para um entendimento de que a solução virá dos próprios países em desenvolvimento, uma vez que os vínculos com os doadores forem rompidos. Há, nesse sentido, uma forte desconsideração da capacidade de autodeterminação dos países em desenvolvimento, identificando a ajuda como vínculo que impede sua emancipação.

O pós-escrito pinta um quadro contraditório, em que nos deparamos com a continuidade de guerras e movimentos políticos perigosos (como se nos espantasse que a história não tivesse se encerrado em 1991, como previra "O fim da história" de Fukuyama (1989), em 1898), mas que mantém uma visão ligeiramente otimista sobre a construção de rotas de fuga. O autor aposta que a desaceleração do crescimento é exagerada pela limitação das mediçóes e que o progresso do conhecimento (e sua disseminação) será capaz de promover maior aproximação nos níveis de bem-estar internacionalmente. Isso se deve, entre outros fatores, à tendência de crescimento da expectativa de vida maior nos países onde essa expectativa é menor, permitindo uma tendência de aproximação nessa área.

O progresso da humanidade, no entanto, é apresentado como um fato, mesmo que se reconheça que ele é, ao mesmo tempo, um potencializador das desigualdades.

Para além da rica exploração de temas de saúde sob uma perspectiva global, que merece ser mencionada e referenciada nos debates contemporâneos de saúde global, outra contribuição do livro às ciências sociais é prover um retrato do discurso econômico em torno da saúde, em um contexto no qual a linguagem econômica predomina nos debates de desenvolvimento, afetando mais do que 
outras ciências sociais as opçóes políticas adotadas por paísese organizaçóes internacionais. A obra é bastante acessível ao público não iniciado nos complexos conceitos econômicos, explicando, de forma detalhada, cálculos de índices correntes no jargão econômico e suas limitaçóes. A tradução, por Marcelo Levy, é excelente, mantendo a fluidez e a clareza da obra no idioma original.

\section{BIBLIOGRAFIA}

FUKUYAMA, Francis. (1989), "The end of history?". The National Interest, 16: 3-18.

THE ROYAL Swedish Academy of Sciences. (2015), "The Prize in Economic Sciences 2015: popular science background”. Disponível em 6702d.https.cdn.softlayer.net/assets/ globalassets-priser-ekonomi-2015-pop_ek_ en_15.pdf, consultado em 13/4/2018. 